Tersedia online di: http://ejournal-balitbang.kkp.go.id/index.php/JP
e-mail:jurnalpari@gmail.com
JURNAL PARI
Volume 4 Nomor 2 Desember 2018
p-ISSN: 2502-0730
e-ISSN : 2549-0133

\title{
UJI PARUH HIDUP (HALF LIFE) PADA ARTIKEL JURNAL RISET AKUAKULTUR
}

\section{ANALYSIS ON HALF LIFE OF ARTICLES JURNAL RISET AKUAKULTUR}

\author{
Erny Puspa \\ Pusat Riset Perikanan \\ Diterima tanggal : 7 Agustus 2018 Diterima setelah perbaikan : 11 Oktober 2018 \\ disetujui terbit : 10 Desember 2018
}

\begin{abstract}
ABSTRAK
kajian mengenai keusangan literatur adalah kajian bibliometrika/infometrika tentang penggunaan dokumen(literatur) yang berkaitan dengan umur literatur tersebut. Metode yang digunakan dalam penelitian ini adalah deskriptif kuantitatif dengan populasi seluruh artikel pada Jurnal Riset Akuakultur tahun 2011 - 2015 yang berjumlah 240 artikel dan 5887sitiran. Hasil penelitian menunjukkan bahwa usia paruh hidup Jurnal Riset Akuakultur tahun 2011-2015 adalah sebesar 14,09 tahun dengan sitiran baru sebanyak 3835 atau sebesar $65,14 \%$ dan jumlah sitiran usang sebanyak 2052 atau sebesar $34,86 \%$. Berdasarkan pernyataan tersebut maka jurnal tersebut dinyatakan memiliki artikel yang mutakhir sehingga dapat dijadikan bahan referensi yang relevan karena sebagian besar sitirannya merupakan literatur terbaru
\end{abstract}

Kata kunci: Jurnal IImiah; bibliometrik; keusangan.

\begin{abstract}
The study of obsolescence literature is a bibliometrics/infometrika test of the use of document (literature) which is associated with its age. The methods used in this research are quantitative descriptive with the population of all articles in 2011-2015 Jurnal Riset Akuakultur which consist of 240 articles and 5887 citations. The research shows that the age of 2011-2015 Jurnal Riset Akuakultur half-life are 14,09 years with 3835 new citations $(65,14 \%)$ and the numbers of outdated citations are 2015 (34,86\%). Therefore, based on that result, the journal has updated articles. Thus, the reference materials in it are relevant since most of the citations are the latest.
\end{abstract}

Keywords: Scientific Journal, bibliometric, obsolescence 


\section{PENDAHULUAN}

Dalam penulisan jurnal ilmiah diperlukan rujukan referensi yang sesuai dengan tingkat keusangan disiplin ilmunya agar karya tulis tersebut menghasil karya yang tetap mutahir dan relevan dan aktual sebagaimana Hartinah dalam Hasugian (2005) umur tingkat keusangan sebuah dokumen berbeda beda menurut disiplin ilmunya, untuk ilmu fisika adalah 4,6 tahun; fisiologi 7,2 tahun; kimia 8,1 tahun; botani 10 tahun; matematika 10,5 tahun; geologi 11,8 tahun; kedokteran 6,8 tahun; hukum 12,9 tahun; dan untuk bidang sosial kurang dari 2 tahun

Kajian Keusangan paruh hidup literatur merupakan bagian dari kajian bibliomerika. Dalam kajian keusangan literatur, hidup diartikan sebagai rentang waktu literatur digunakan sebanyak 50\% (separuh) penggunaan total dokumen itu. Usia hidup literatur perlu dikaji agar dapat memberikan gambaran keakuratan dan kerelevanan informasi dari isi literatur tersebut. Kerelevanan isi sebuah literatur dapat memberi gambaran kemutakhiran isi dari sebuah karya ilmiah, sedangkan kemutakhiran isi dapat memberi gambaran tentang perkembangan disiplin bidang ilmu tersebut.( Maulidina, 2012)

Berdasar uraian diatas penulis tertarik mengkaji usia hidup pada Jurnal Riset Akuakultur. Jurnal Riset Akuakultur merupakan jurnal ilmiah yang diterbitkan Pusat Riset Perikanan yang terbit pada tahun 2006 hingga saat ini. Dengan kala terbit dari tahun 2006 2014 sebanyak 3 kali setahun, kemudian tahun 2015 hingga saat ini terbit 4 kali setahun dikarenakan bertambahnya karya tulis ilmiah yang masuk pada terbitan Jurnal Riset Akukaultur

Pada kajian ini penulis membuat batasan masalah dengan mengkaji per 5 tahun terbitan yaitu dari Jurnal Riset Akuakultur tahun 20112015, sedangkan untuk Jurnal Riset akuakutur tahun 2016-2020 akan dilakukan pada kajian berikutnya

Tujuan dibuat kajian paru hidup pada Jurnal Riset Akuakultur agar dapat diketahui tingkat keusangan dan usia paruh hidup terhadap literatur Jurnal Riset Akuakultur. Sehingga dapat diketahui apakah jurnal tersebut menyediakan informasi yang relevan.

\section{TINJAUAN PUSTAKA}

\section{Jurnal IImiah}

Jurnal ilmiah merupakan majalah yang diterbitkan secara berkala yang berisi artikel artikel ilmiah yang dan ditulis sesuai kaidah KTI dan dipublikasikan sesuai dengan disyaratkan oleh Lembaga IImu Pengetahuan Indonesia, hal ini senada dengan pendapat Hakim (2012) jurnal ilmiah adalah "majalah publikasi yang memuat KTI (karya tulis ilmiah) yang secara nyata mengandung data dan informasi yang mengajukan iptek dan ditulis sesuai dengan kaidah-kaidah penulisan ilmiah serta diterbitkan secara berkala".

Adapun kaidah kaidah $\mathrm{KTI}$ (karya tulis ilmiah) terdiri atas sifat-sifat berikut (Irmawati, 2015)

1. Logis, berarti berunutan penjelasan dari data dan informasi yang masuk ke dalam logika pemikiran kebenaran ilmu.

2. Obyektif, berarti data dan informasi sesuai dengan fakta kebenarannya.

3. Sistematis, berarti sumber data dan informasi yang diperoleh dari hasil kajian dengan mengikuti urutan pola pikir yang sistematis atau litbang yang konsisten/berkelanjutan.

4. Andal, berarti data dan informasi yang telah teruji dan sahih serta masih memungkinkan untuk terus dikaji ulang.

5. Desain, berarti terencanakan dan memiliki rancangan, dan

6. Akumulatif, berarti kumpulan dari berbagai sumber yang diakui kebenaran dan keberadaannya serta memberikan kontribusi bagi khasanah iptek yang sedang berkembang.

Adapun bentuk penerbitan Jurnal ilmiah sebagaimana yang ditentukan oleh Lembaga IImu Penelitian Indonesia (2012) wajib memenuhi persyaratan administratif sebagai berikut

1. Terdapat International Standard Serial Number (ISSN)dalam terbitan tersebut

2. Tedapat mitra bestari minimal 4 (empat) orang.

3. Kala terbit secara rutin dan berkala.

4. Bertiras tiap kali penerbitan paling sedikit berjumlah 300 eksemplar.

5. Memuat artikel utama tiap kali penerbitan yang berjumlah paling sedikit 5 (lima) buah.

6. Artikel yang dimuat paling sedikit 5 buah tiap kali penerbitan

Manfaat Jurnal ilmiah selain sebagai sarana diseminasi hasil penelitian disiplin ilmu tertentu juga sebagai barometer hasil penelitian suatu instasi dan lembaga tertentu sehingga terbuka peluang terjadinya komunikasi antar peneliti dalam hal pembanding dan pengembangan penelitian juga mencegah terjadinya 
penjiplakan atau plagiat hasil penelitian

\section{Bibliometrika}

Bibliometrika berasal dari bahasa Yunani yaitu dari kata biblio atau bibliography dan metrics, biblio berkaitan dengan mengukur. Jadi bibliometrik berarti mengukur atau menganalisis buku/literatur dengan menggunakan pendekatan matematika dan statistika (Hartinah, 2002)

Menurut Pritchard dalam Mustikasari (2008) yaitu: "bibliometrika adalah aplikasi metode statistika dan matematika terhadap buku dan media lainnya dari komunikasi terekam".

Pendapat yang lebih kompleks dinyatakan oleh Boyce, et al dalam Mustikasari (2008) yaitu "bibliometrika merupakan studi mengenai produksi dan penyebaran informasi yang secara operasional dikaji melalui produksi dan penyebaran media yang merekam informasi untuk disimpan dan disebarluaskan".

Dapat disimpulkan bibliometrika merupakan kajian untuk menganalisa buku, literatur, karya cetak dan karya rekap dengan kajian kuantitatif dengan pendekatan matematika dan stasistik untuk disimpan dan disebarluaskan dan pada umumnya kajian bibliometrik lebih banyak ditujukan kepada majalah ilmiah, karena majalah kajian bibliometrik, karena lebih banyak ditujukan kepada majalah lilmiah majalah jenis ini diangap menduduki peran (ter) penting dalam komunikasi ilmiah (Basuki, 1990)

\section{Keusangan Literatur}

Istilah Keusangan literatur (Obsolescence) berasal dari kata "obsolete" berarti out-of-date, no longer in use, no longer valid atau no longer fashionable. Menurut Mustafa (2008) Keusangan literatur adalah kajian bibliometrika/informetrika tentang penggunaan dokumen (literatur) yang berkaitan dengan umur literatur tersebut

Melalui kajian keusangan literatur dapat diketahui tingkat pemanfaatan literatur/dokumen/koleksi apakah mengalami pengurangan atau sebaliknya. Apabila literatur/dokumen kurang/jarang dimanfaatkan maka dapat sebagai acuan dilakukan kebijakan penyiangan literatur/dokumen/koleksi pada perpustakaan sehingga tingkat kemutakhiran literatur/ dokumen atau koleksi perpustakaan tetap terpelihara
Penyebab keusangan literatur dikarenakan adanya perkembangan ilmu pengetahuan. Hal itu terjadi karena ilmuwan lebih dominan menggunakan informasi yang mutakhir, menarik dan aktual, sedangkan informasi yang sudah tua cenderung digunakan saat informasi tersebut relevan saja. Hal ini Sebagaimana pendapat Mustafa,(2010)

"Adanya perkembangan dari ilmu pengetahuan mengakibatkan munculnya fenomena keusangan literatur. Fenomena tersebut terjadi ketika dimana hanya literatur yang mutakhir serta menarik saja yang digunakan oleh ilmuan. Sedangkan literatur tua digunakan hanya bila mengandung informasi yang cenderung menggabungkan karya yang terakhir kali terbit"

Dari uraian diatas disimpulkan bahwa keusangan literatur merupakan kajian bibliometrika yang ditandai dengan berkurangnya pemanfaatan suatu dokumen/ literature yang disebabkan faktor usia dokumen tersebut akibat dari perkembangan bidang ilmu tersebut sehingga menciptakan terbitan terbitan lebih mutakhir yang lebih banyak diminati oleh masyarakat

\section{METODE}

\section{Jenis Penelitian}

Dalam penelitian ini penulis menggunakan jenis penelitian kuantitatif dengan metode deskriptif. Setyosari (2010) menjelaskan bahwa penelitian deskriptif adalah "Penelitian yang bertujuan untuk menjelaskan atau mendeskripsikan suatu keadaan, peristiwa, objek apakah orang, atau segala sesuatu yang terkait dengan variabel-variebel yang bisa dijelaskan baik dengan angka-angka maupun kata-kata".

Dalam kajian ini objek yang diteliti adalah seluruh daftar pustaka pada masing-masing artikel yang terdapat pada "Jurnal Riset Akuakultur " terbitan dari tahun $2011-2015$

Dari tabel 2 diatas dapat diketahui bahwa pada Jurnal Riset Akuakultur dalam kurun waktu 5 tahun (2011-2015) terdapat 240 artikel dengan jumlah 5887 sitiran, dengan jumlah artkel dan sitiran paling banyak pada tahun 2015 berjumlah 60 artikel dan 1486 sitiran hal ini dikarenakan pada kurun tahun 2006-2014 terbit dari 3 kali dalam setahun dan semenjak tahun 2015 menjadi 4 kali dalam setahun 
Tabel 1. Unit Analisis Jurnal Riset Akuakultur

\begin{tabular}{|c|c|c|c|c|}
\hline \multirow{2}{*}{ No. } & \multicolumn{2}{|c|}{ Tahun dan Volume } & \multirow{2}{*}{ Artikel } & \multirow{2}{*}{$\begin{array}{l}\text { Jumlah } \\
\text { Sitiran }\end{array}$} \\
\hline & Tahun & Volume & & \\
\hline 1 & 2011 & 6.1 & 15 & 325 \\
\hline 2 & 2011 & 6.2 & 15 & 349 \\
\hline 3 & 2011 & 6.3 & 15 & 368 \\
\hline 4 & 2012 & 7.1 & 15 & 295 \\
\hline 5 & 2012 & 7.2 & 15 & 350 \\
\hline 6 & 2012 & 7.3 & 15 & 395 \\
\hline 7 & 2013 & 8.1 & 15 & 404 \\
\hline 8 & 2013 & 8.2 & 15 & 375 \\
\hline 9 & 2013 & 8.3 & 15 & 367 \\
\hline 10 & 2014 & 9.1 & 15 & 390 \\
\hline 11 & 2014 & 9.2 & 15 & 409 \\
\hline 12 & 2014 & 9.3 & 15 & 374 \\
\hline 13 & 2015 & 10.1 & 15 & 405 \\
\hline 14 & 2015 & 10.2 & 15 & 431 \\
\hline 15 & 2015 & 10.3 & 15 & 336 \\
\hline 16 & 2015 & 10.4 & 15 & 314 \\
\hline \multicolumn{3}{|c|}{ Jumlah } & 240 & 5887 \\
\hline
\end{tabular}

Tabel2. Rekapitulasi Unit Analisis Skala Jurnal Riset Akuakultur

\begin{tabular}{|c|c|c|c|}
\hline \multirow{2}{*}{ No. } & \multirow{2}{*}{ Tahun } & \multicolumn{2}{|c|}{ Jumlah Sitiran } \\
\hline & & Artikel & Sitiran \\
\hline 1 & 2011 & 45 & 1042 \\
\hline 2 & 2012 & 45 & 1040 \\
\hline 3 & 2013 & 45 & 1146 \\
\hline 4 & 2014 & 45 & 1173 \\
\hline 5 & 2015 & 60 & 1486 \\
\hline \multicolumn{2}{|c|}{ Jumlah } & 240 & 5887 \\
\hline
\end{tabular}

\section{Pengolahan}

\section{Data Usia Paruh Hidup}

Berdasar data pada tabel 2 kemudian dilakukan perhitungan usia paruh hidup dengan menggunakan rumus median :

$$
M d=L m d+\frac{(J m d)}{(\text { Fmd })} i
$$

Keterangan:

Md = Median

Lmd = Kelas nyata bawah pada saat frekuensi kumulatif mengandung $\mathrm{n} / 2$

Jmd = Selisih $\mathrm{n} / 2$ dengan frekuensi kumulatif mengandung $\mathrm{n} / 2$
Fmd = Frekuensi pada saat frekuensi kumulatif mengandung $\mathrm{n} / 2$

I = Interval

(Sturges dalam Syamsudin 2002)

Namun sebelum menggunakan rumus paruh hidup tersebut, harus dilakukan dulu langkah-langkah sebagai berikut:

1. Penentuan kelas atau kelompok data $K=1+3,322$ $\log _{n}(n$ adalah banyaknya jumlah sitiran dalam jurnal)

2. Menghitung tahun terbit tertinggi dan terendah

$\mathrm{R}=\mathrm{X}_{\mathrm{n}}-\mathrm{X}_{1}$
3. Menghitung interval $I=\frac{R}{K}$

4. Membuat tabel distribusi frekuensi kumulatif

5. Menghitung usia paruh hidup dengan cara $X_{n}-M_{d}$

Keterangan:

$X_{n}=$ Tahun termuda

$X_{1}=$ Tahun tertua

$\mathrm{K}=$ Kelas adalah banyaknya kelompok tahun terbit sitiran

$\mathrm{R}=$ Range adalah selisih tahun terbit sitiran tertinggi dengan tahun terbit sitiran terendah

$\mathrm{I}=$ Interval adalah batas atas dan batas bawah kelompok tahun terbit sitiran

\section{Interpretasi Data}

Setelah melakukan perhitungan di atas maka interpretasi data dapat dijabarkan sebagai berikut:

1. Usia hidup merupakan hasil dari pengurangan antara tahun sitiran termuda dengan tahun median. Semakin tinggi usia paruh hidup maka dapat dikatakan perkembangan ilmu pada bidang tersebut berjalan lambat.

2. Sitiran yang dianggap usang adalah sitiran yang tahunnya lebih kecil dari tahun median.

3. Sitiran yang dianggap valid adalah sitiran yang tahunnya lebih besar atau sama dengan tahun median

\section{PEMBAHASAN}

hidup pada Jurnal Riset Akuakultur Pusat Riset Perikanan yang terbit dari tahun 2011 - 2015 dapat dihitung dengan cara sebagaimana (Hasugian, 2010) yaitu dengan cara mencari angka median dari seluruh dokumen yang disitir setelah terlebih dahulu mengurutkan semua dokumen yang disitir mulai dari tertua (tahun terkecil) sampai yang terbaru (tahun terbesar) atau sebaliknya. Kemudian dicari median yang membagi daftar referensi yang sudah berurut tersebut menjadi dua bagian masing-masing 50\%. Median ini menunjukkan hidup dokumen pada bidang 
yang terkait. Faktor yang mempengaruhi adanya hidup dokumen pada suatu bidang adalah jumlah penggunaan dokumen, jumalh publikasi dalam bidang tersebut dan jumlah penulis pada bidangnya. Secara rinci dapat dijabarkan langkah-langkat penghitungan usia paruh hidup sebagai berikut:

Diketahui:

- $\quad$ Tahun terbit sitiran tertinggi $\left(X_{n}\right)=2015$

- $\quad$ Tahun terbit sitiran terendah $\left(X_{n}\right)=1910$ - Jumlah sitiran $=5887$

Ditanya :

1. Md (Median)

2. Usia Hidup

$=?$

$=$ ?

Berikut adalah proses perhitungannya:

1. Penentuan kelompok kelas

$$
\begin{aligned}
K & =1+3,322 \cdot \log _{n} \\
& =1+3,322 \cdot \log 5887 \\
& =1+12,5236 \\
& =13,5236
\end{aligned}
$$

2. Penentuan range

$$
\begin{aligned}
\mathrm{R} & =\mathrm{X}_{\mathrm{n}}-\mathrm{X}_{1} \\
& =2015-1910 \\
& =105
\end{aligned}
$$

3. Penentuan Interval

$$
\begin{aligned}
I & =\frac{R}{K} \\
& =\frac{105}{13,5236} \\
& =7,7642 \\
& =8
\end{aligned}
$$

Selanjutnya berdasarkan data di atas dapat disusun tabel distribusi frekuensi untuk menghitung usia paruh hidup dokumen yang disitir oleh Jurnal Riset Akuakultur yang terbit dari tahun 2011 - 2015, sebagai berikut:

Tabel 3. Distribusi Frekuensi Literatur Tahun 2011 - 2015

\begin{tabular}{|c|c|c|c|}
\hline \multirow{2}{*}{$\begin{array}{c}\text { Periode } \\
\text { Tahun Terbit }\end{array}$} & \multicolumn{2}{|c|}{ Frekuensi } & \multirow{2}{*}{ Presentase } \\
\cline { 2 - 3 } & Sitiran & Kumulatif & \\
\hline $1910-1917$ & 1 & 1 & 0,02 \\
\hline $1918-1925$ & 0 & 1 & 0,00 \\
\hline $1926-1933$ & 0 & 1 & 0,00 \\
\hline $1934-1941$ & 2 & 3 & 0,03 \\
\hline $1942-1949$ & 0 & 3 & 0,00 \\
\hline $1950-1957$ & 4 & 7 & 0,07 \\
\hline $1958-1965$ & 34 & 41 & 0,58 \\
\hline $1966-1973$ & 97 & 138 & 1,65 \\
\hline $1974-1981$ & 241 & 379 & 4,09 \\
\hline $1982-1989$ & 461 & 840 & 7,83 \\
\hline $1990-1997$ & 1056 & 1896 & 17,94 \\
\hline $1998-2005$ & 1773 & 3669 & 30,12 \\
\hline $2006-2013$ & 2134 & 5803 & 36,25 \\
\hline $2014-2021$ & 84 & 5887 & 1,43 \\
\hline Jumlah & 5887 & & 100,00 \\
\hline
\end{tabular}

$\mathrm{N} / 2=5887 / 2=2943,5$

Maka kelas nyata bawah pada saat frekuensi kumulatif mengandung $n / 2$ jatuh di tahun 1998. Jadi kelas nyata bawahnya yaitu $1998-0,5=1997,5$. Maka, Lmd = 1997,5.

Frekuensi pada saat frekuensi kumulatif mengandung $\mathrm{n} / 2$ jatuh pada jumlah sitiran yang kurun waktunya antara tahun $1998-2005$ yaitu 1773. Maka, $\mathrm{Fmd}=1773$.
Selisih $\mathrm{n} / 2$ dengan frekuensi kumulatif mengandung $\mathrm{n} / 2$ jatuh pada frekuensi sitiran 3669 , maka selisih dengan frekuensi kumulatif mengandung adalah 3669 - 2943,5 = 699,5. Maka, Jmd = 755,5

$$
\begin{aligned}
& M d=L m d+\frac{(\text { Jmd })}{(\text { Fmd })} \cdot i \\
& M d=1997,5+\frac{(755,5)}{(1773)} \cdot 8 \\
& M d=1997,5+3,4089 \\
& M d=2000,91
\end{aligned}
$$


Maka usia paruh hidup Jurnal Riset Akuakultur yang terbit dari tahun 2011-2015adalah:

$$
\begin{array}{ll}
= & \mathrm{Xn}-\mathrm{Md} \\
= & 2015-2000,91 \\
= & 14,09 \text { tahun } \\
= & 14 \text { tahun }
\end{array}
$$

Dengan melihat perhitungan di atas dapat diketahui bahwa usia paruh hidup Jurnal Riset Akuakultur yang terbit dari tahun $2011-2015$ adalah 14 tahun. Hal ini berarti sitiran yang disitir dibawah tahun 2000,91 sebanyak 2052 sitiran dianggap usang atau sebesar $34,86 \%$, sedangkan sitiran yang disitir di atas tahun 2000,65 sebanyak 3835 sitiran merupakan sitiran yang baru atau sebesar $65,14 \%$ dianggap valid. Hal ini menunjukkan bahwa literatur pada jurnal riset tersebut layak dimuat sebagai sitiran.

\section{KESIMPULAN}

kajian mengenai keusangan literatur adalah kajian bibliometrika/infometrika tentang penggunaan dokumen(literatur) yang berkaitan dengan umur literatur tersebut. Metode yang digunakan dalam penelitian ini adalah deskriptif kuantitatif dengan populasi seluruh artikel pada Jurnal Riset Akuakultur tahun 2011 - 2015 yang berjumlah 240 artikel dan 5887sitiran. Hasil penelitian menunjukkan bahwa usia paruh hidup Jurnal Riset Akuakultur tahun 2011-2015 adalah sebesar 14,09 tahun dengan sitiran baru sebanyak 3835 atau sebesar $65,14 \%$ dan jumlah sitiran usang sebanyak 2052 atau sebesar $34,86 \%$. Berdasarkan pernyataan tersebut maka jurnal tersebut dinyatakan memiliki artikel yang mutakhir sehingga dapat dijadikan bahan referensi yang relevan karena sebagian besar sitirannya merupakan literatur terbaru

\section{DAFTAR PUSTAKA}

Basuki, S. 1990. Kolaborasi pengarang sebuah kajian bibliometrik: Majalah Ikatan Pustakawan Indonesia 12(2-3): 12-18.

Hakim. 2012. Penyusunan Karya Tulis IImiah. https:/ laminawm.wordpress.com/pengertian-jurnalilmiah/ Diakses 14 Juli 2018
Hartinah, S. 2002. Keusangan dan hidup literatur dalam Kumpulan makalah kursus bibliometrika, Sulistyo-Basuki. Depok: Masyarakat Informetrika Indonesia

Hasugian, J. 2005. Analisis Sitiran terhadap Disertasi Program Doktor (S-3) IImu Kedokteran Sekolah Pascasarjana Universitas Sumatera Utara. [on line]. http://repository.usu.ac.id/bitstream/ 123456789/15749/1/pus-des2005-\%20.pdf/ diakses 20 Juni 2018

Hasugian, J. 2010. Dasar-Dasar IImu Perpustakaan.Bogor: Ghalia Indonesia

Irmawati, N. 2015. Karangan IImiah,wordpress.com/ 2015/01/19/karangan-ilmiah/diakses 14 Juli 2018

Lembaga IImu Pengetahuan Indonesia .2012. Pedoman Penerbitan Buku.Jakarta : LIPI

Mustikasari, E R F . 2008. Pendekatan Bibliometrik dalam Komunikasi Ilmiah. [On

line]. Diakses dalam http://repository.usu.ac.id/ bitstream/123456789/17852 diakses 9 Agustus 2018

Maulida, W. 2012. Analisis Hidup Usia Dokumen Yang Disitir Artikel Pada Jurnal Annals Of Library And Information Studies (Alis) Periode 2002 - 2011, https://text-id.123dok.com/document/eqo53vjyanalisis-hidup-usia-dokumen-yang-disitir-artikelpada-jurnal-annals-of-library-and-information-studies-alis-periode-2002-2011.html/diakses 20 Juni 2018

Mustafa, B. 2010. Obsolescence: mengenal konsep keusangan literatur dalam dunia kepustakawanan , https://repository.ipb.ac.id/handle/123456789/ 32139/diakses 8 Oktober 2018

Setyosari, P. 2010. Metode Penelitian Penelitian dan Pengembangan. Jakarta: Kencana.

Syamsudin. 2002. Statistik Deskriptif. Surakarta : Muhammadiyah University Press 